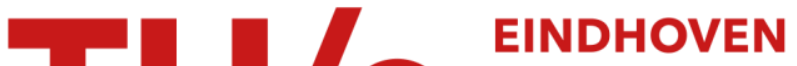 UNIVERSITY OF TECHNOLOGY
}

\section{Early in-situ cellularization of a supramolecular vascular graft is modified by synthetic stromal cell-derived factor-1 $\alpha$ derived peptides}

\author{
Citation for published version (APA): \\ Muylaert, D. E. P., van Almen, G. C., Talacua, H., Fledderus, J., Kluin, J., van Dongen, J. L. J., Hendrikse, S., \\ Sijbesma, E., Bosman, A. W., Mes, T., Thakkar, S. H., Smits, A. I. P. M., Bouten, C. V. C., Dankers, P. Y. W., \& \\ Verhaar, M. C. (2016). Early in-situ cellularization of a supramolecular vascular graft is modified by synthetic \\ stromal cell-derived factor-1a derived peptides. Biomaterials, 76, 187-195. \\ https://doi.org/10.1016/j.biomaterials.2015.10.052
}

\section{Document license: \\ TAVERNE}

DOI:

10.1016/j.biomaterials.2015.10.052

Document status and date:

Published: 01/01/2016

\section{Document Version:}

Publisher's PDF, also known as Version of Record (includes final page, issue and volume numbers)

\section{Please check the document version of this publication:}

- A submitted manuscript is the version of the article upon submission and before peer-review. There can be important differences between the submitted version and the official published version of record. People interested in the research are advised to contact the author for the final version of the publication, or visit the DOI to the publisher's website.

- The final author version and the galley proof are versions of the publication after peer review.

- The final published version features the final layout of the paper including the volume, issue and page numbers.

Link to publication

\footnotetext{
General rights

- You may freely distribute the URL identifying the publication in the public portal. follow below link for the End User Agreement:

www.tue.nl/taverne

\section{Take down policy}

If you believe that this document breaches copyright please contact us at:

openaccess@tue.nl

providing details and we will investigate your claim.
}

Copyright and moral rights for the publications made accessible in the public portal are retained by the authors and/or other copyright owners and it is a condition of accessing publications that users recognise and abide by the legal requirements associated with these rights.

- Users may download and print one copy of any publication from the public portal for the purpose of private study or research.

- You may not further distribute the material or use it for any profit-making activity or commercial gain

If the publication is distributed under the terms of Article $25 \mathrm{fa}$ of the Dutch Copyright Act, indicated by the "Taverne" license above, please 


\title{
Early in-situ cellularization of a supramolecular vascular graft is modified by synthetic stromal cell-derived factor- $1 \alpha$ derived peptides
}

\author{
Dimitri E.P. Muylaert ${ }^{a}$, Geert C. van Almen ${ }^{\text {b, }}{ }^{\text {, }}$ Hanna Talacua ${ }^{\mathrm{d}}$, Joost O. Fledderus ${ }^{\mathrm{a}}$, \\ Jolanda Kluin d, Simone I.S. Hendrikse b, c, Joost L.J. van Dongen b, e, Eline Sijbesma b, c, \\ Anton W. Bosman ${ }^{\text {f }}$, Tristan Mes ${ }^{\text {f }}$, Shraddha H. Thakkar ${ }^{g}$, Anthal I.P.M. Smits ${ }^{\text {b, g }}$, \\ Carlijn V.C. Bouten ${ }^{\text {b, g, }}$, Patricia Y.W. Dankers ${ }^{\text {b, c, g, }{ }^{*}, 1}$, Marianne C. Verhaar ${ }^{\text {a, }}{ }^{\text {}}$ \\ ${ }^{a}$ Department of Nephrology and Hypertension, University Medical Center Utrecht, The Netherlands \\ ${ }^{\mathrm{b}}$ Institute for Complex Molecular Systems, Eindhoven University of Technology, Eindhoven, The Netherlands \\ c Department of Biomedical Engineering, Laboratory of Chemical Biology, Eindhoven University of Technology, Eindhoven, The Netherlands \\ d Department of Cardiothoracic Surgery, Academic Medical Center Amsterdam/Leiden University Medical Center, The Netherlands \\ e Department of Chemical Engineering and Chemistry, Laboratory of Macromolecular and Organic Chemistry, Eindhoven University of Technology, \\ Eindhoven, The Netherlands \\ ${ }^{f}$ SupraPolix BV, Eindhoven, The Netherlands \\ ${ }^{\mathrm{g}}$ Department of Biomedical Engineering, Laboratory for Cell and Tissue Engineering, Eindhoven University of Technology, Eindhoven, The Netherlands
}

\section{A R T I C L E I N F O}

\section{Article history:}

Received 9 July 2015

Received in revised form

13 October 2015

Accepted 18 October 2015

Available online 23 October 2015

\section{Keywords:}

Supramolecular

Cell free graft

Cardiovascular tissue engineering

SDF1a

Bioactive scaffold

Stromal cell derived factor

\begin{abstract}
A B S T R A C T
In an in-situ approach towards tissue engineered cardiovascular replacement grafts, cell-free scaffolds are implanted that engage in endogenous tissue formation. Bioactive molecules can be incorporated into such grafts to facilitate cellular recruitment. Stromal cell derived factor $1 \alpha$ (SDF1 $\alpha$ ) is a powerful chemoattractant of lymphocytes, monocytes and progenitor cells and plays an important role in cellular signaling and tissue repair. Short SDF1 $\alpha$-peptides derived from its receptor-activating domain are capable of activating the SDF1 $\alpha$-specific receptor CXCR4. Here, we show that SDF1 $\alpha$-derived peptides can be chemically modified with a supramolecular four-fold hydrogen bonding ureido-pyrimidinone (UPy) moiety, that allows for the convenient incorporation of the UPy-SDF1 $\alpha$-derived peptides into a UPy-modified polymer scaffold. We hypothesized that a UPy-modified material bioactivated with these UPy-SDF1 $\alpha$-derived peptides can retain and stimulate circulating cells in an anti-inflammatory, protissue formation signaling environment. First, the early recruitment of human peripheral blood mononuclear cells to the scaffolds was analyzed in vitro in a custom-made mesofluidic device applying physiological pulsatile fluid flow. Preferential adhesion of lymphocytes with reduced expression of inflammatory factors TNF $\alpha$, MCP1 and lymphocyte activation marker CD25 was found in the bioactivated scaffolds, indicating a reduction in inflammatory signaling. As a proof of concept, in-vivo implantation of the bioactivated scaffolds as rat abdominal aorta interposition grafts showed increased cellularity by CD68+ cells after 7 days. These results indicate that a completely synthetic, cell-free biomaterial can attract and stimulate specific leukocyte populations through supramolecular incorporation of short bioactive SDF1 $\alpha$ derived peptides.
\end{abstract}

(c) 2015 Elsevier Ltd. All rights reserved.

\section{Introduction}

Replacement of small diameter blood vessels relies mainly on

\footnotetext{
* Corresponding author. Department of Biomedical Engineering, Laboratory of Chemical Biology, Eindhoven University of Technology, Eindhoven, The Netherlands.

E-mail address: p.y.w.dankers@tue.nl (P.Y.W. Dankers).

${ }^{1}$ These authors contributed equally to this work.
}

autologous tissue, which is often limited by availability and requires invasive harvesting. Common non-living prostheses for vascular structures have considerable drawbacks such as high risk of occlusion, lack of growth potential, the consequent need for reoperation in pediatric patients, and life-long anti-coagulation therapy [1]. In an in-situ tissue engineering approach, synthetic scaffolds are implanted that provide the necessary mechanical support. Ideally, scaffold material will contain bioactive molecules capable of instructing cells of the recipient to migrate into the graft 
and stimulate the development of living, growing tissue [2]. Molecules involved in cellular adhesion have largely been the focus to be introduced in synthetic materials [3]. Chemokines play a considerable role in the process of tissue repair by attracting progenitor cells but also by modulating the inflammatory environment. Therefore, immobilization of chemokines on synthetic grafts may simultaneously allow for both specific cell retention and subsequent stimulation of cellular development [2]. Stromal cell derived factor 1 alpha (SDF1 $\alpha$ ) is a potent chemoattractant of lymphocytes [4], monocytes and progenitor cells but not neutrophils [5]. It is important for the homing of bone-marrow resident stem cells [6], and plays a central role in tissue repair signaling [5]. Importantly, following implantation the systemic response to a cell-free vascular graft material involves the influx of immune cells. The nature and amount of these cells can be influenced by SDF1 $\alpha$ [7]. Short SDF1 $\alpha$-peptides that are homologous to the receptoractivating domain of the full protein, have been shown to improve damage repair after local delivery in ischemic tissue [8]. This indicates that short peptide sequences, which are synthetically more accessible compared to full-length proteins, are capable of retaining specific SDF1 $\alpha$ activity. Maintaining a stable local gradient of SDF $1 \alpha$ and avoiding a burst release of bioactive molecules after implantation has been shown to further improve the retention of progenitor cells under fluid flow conditions [9]. In addition to inducing cellular mobilization as a soluble factor, SDF1a is an important anchoring molecule for progenitor cells in bone marrow stroma [10] as well as a homing beacon bound to the ECM in the vicinity of tissue damage, guiding the migration of cells towards the site of repair [11]. Therefore an approach to anchor the SDF1 $\alpha$ protein to a scaffold material may be advantageous for biological signaling at the site of graft implantation.

In this study we apply a synthetic cell-free scaffold based on the supramolecular modification of poly(L-lactic acid caprolactone) (PLLCL) functionalized with quadruple hydrogen bonding ureidopyrimidinone (UPy) units [12], with SDF1 $\alpha$-derived peptide sequences also modified with these UPy-moieties, in order to facilitate the early cellularization of a vascular graft [2]. The base material consists of PLLCL prepolymers modified with UPy-moieties in the main chain yielding a chain-extended UPy-PLLCL (or CE-UPy-PLLCL) polymer (Fig. 1) [13]. To prevent rapid proteolytic degradation of the SDF1 $\alpha$-derived peptides, we abolished the cleavage sites for the enzymes MMP2 and CD26, which are capable of abrogating the SDF1 $\alpha$ signal and are abundant in an inflammatory environment $[8,14]$. The second valine in the natural sequence was substituted with a serine residue, leading to two peptide sequences: SKPVSLSYR and SKPVVLSYR, i.e. the proteolytically resistant and non-resistant peptides, respectively (after UPy-modification UPy-SDF1 $\alpha(R)$ and UPy-SDF $1 \alpha(\mathrm{NR})$, respectively). The material was processed into fibrous scaffolds by electrospinning. Using a previously developed mesofluidic device [15] applying a physiological pulsatile fluid flow of medium-suspended human peripheral blood mononuclear cells (PBMCs) the homing of cells into the scaffolds functionalized with short SDF1 $\alpha$ peptides was analyzed. As a proof-of-concept to investigate the in vivo specific recruitment of circulating cells, we implanted electrospun tubular scaffolds in a abdominal aorta interposition graft rat model and analyzed the cellular influx after $24 \mathrm{~h}$ and 7 days.

\section{Materials and methods}

\subsection{Synthesis of UPy-peptide materials}

\subsubsection{Synthesis of the SDF1 $\alpha$ peptides}

The synthesis of the investigated peptides is described in the supplemental files (See supplemental Materials \& Methods).

\subsubsection{Synthesis of CE-UPy-PLLCLa}

The CE-UPy-PLLCL polymer was obtained using the same procedure as described for polymer 2 described in Ref. [13] (chain-extended UPy-poly[2-methyl-1,3-propylene adipate) in which the poly[2-methyl-1,3-propylene adipate diol is replaced with poly(L-lactic acid caprolactone) diol (purchased from SyMO-Chem BV) with a $\mathrm{M}_{\mathrm{n}}$ of $1 \mathrm{kDa}$. The CE-UPy-PLLCL polymer was obtained as an elastic solid after two times precipitation in methanol from chloroform. GPC (in chloroform based on polystyrene standards): $\mathrm{M}_{\mathrm{n}}=10.5 \mathrm{~kg} / \mathrm{mol}$, $\mathrm{M}_{\mathrm{W}}=15.2 \mathrm{~kg} / \mathrm{mol}$. DSC (1st heating run at $20{ }^{\circ} \mathrm{C} / \mathrm{min}$ ): $\mathrm{T}_{\mathrm{g}}=-3{ }^{\circ} \mathrm{C}, \mathrm{T}_{\mathrm{m}}=97{ }^{\circ} \mathrm{C} \mathrm{J} / \mathrm{g}$ with a corresponding enthalpy change of $\Delta \mathrm{H}_{\mathrm{m}}=0.78 \mathrm{~J} / \mathrm{g}$.

\subsubsection{Electrospinning}

Electrospinning was used to produce fibrous tubular grafts. Three different conditions were investigated; i.e. I) CE-UPyPLLCL + UPy-SDF $\alpha(R)$, II) CE-UPy-PLLCL + UPy-SDF1 $\alpha(N R)$, and III) CE-UPy-PLLCL without peptides (control) (Fig. 1). CE-UPy-PLLCL and either the UPy-SDF1 $\alpha(\mathrm{R})$ peptide or the UPy-SDF1 $\alpha(\mathrm{NR})$ peptide, were dissolved in a mixture of chloroform $\left(\mathrm{CHCl}_{3}\right)$ : hexafluoroisopropanol (HFIP) $(85: 15 \mathrm{v} / \mathrm{v})$ at a final concentration of $1.1 \mathrm{~mol} \%$ UPy-peptide and a $15 \% \mathrm{w} / \mathrm{v}$ polymer solution Prior to electrospinning, $5 \mathrm{~mL}$ of this solution was prepared on the same day. The polymer solution was stirred for $2 \mathrm{~h}$ on a magnetic stirrer at 200-250 rpm at room temperature.

Fibrous meshes and vascular grafts were electrospun using a climate controlled electrospinning apparatus (IME Technology, Geldrop, NL). The polymer solution was delivered to a metallic needle with a syringe pump connected with 19G capillary. One end of the power supply was connected to the metallic needle and other end to the target. Meshes were spun at $12 \mathrm{kV}$, using a feed rate of $0.050 \mathrm{~mL}$ per minute and a tip-to-target distance of $18 \mathrm{~cm}$. Micrometer thick fibers were deposited on a grounded needle (10 cm in length) with an internal diameter of $18 \mathrm{~mm}$ that rotated at $100 \mathrm{rpm}$. Vascular grafts were spun in a similar manner to the meshes with the exception of the following parameters; a voltage of $20 \mathrm{kV}$ with a feed rate of $0.025 \mathrm{~mL}$ per minute, at a tip-to-target distance of $20 \mathrm{~cm}$ and collection on a rotating target with an internal diameter of $2.1 \mathrm{~mm}$, yielding a tube-like scaffold. All grafts were spun under controlled temperature of $23{ }^{\circ} \mathrm{C}$ and relative humidity of $25 \%$. After complete removal of residual solvent by overnight drying in vacuo, the scaffolds were removed from the collector needle by wetting the scaffold in milliQ water for $1 \mathrm{~min}$, gently loosening the scaffold from the target, followed by an additional $2 \mathrm{~min}$ in milliQ water before completely removing the graft. Subsequently, the excess of solvent and water was removed by drying in vacuo at $21^{\circ} \mathrm{C}$ for $24 \mathrm{~h}$.

\subsubsection{SEM analysis}

In order to study the fibrous morphology and the exact fiber dimensions of the scaffolds scanning electron microscopy imaging using FEI Quanta 600 and Xt Microscope Control software was performed. Samples of comparable size and thickness were fixed on a metal stub using adhesive conductive carbon tape, and imaged under high vacuum $\left(<1.3 \cdot 10^{-4}\right.$ mbar $)$ conditions. Secondary electrons were detected with an accelerating voltage of $1-2 \mathrm{kV}$ and a working distance of $10 \mathrm{~mm}$.

Samples (containing cells) from the pulsatile flow bioreactor experiments were fixed in $1.5 \%$ glutaraldehyde for $24 \mathrm{~h}$ before being washed with PBS and dehydrated in a graded alcohol series, and imaged with SEM as described above. 


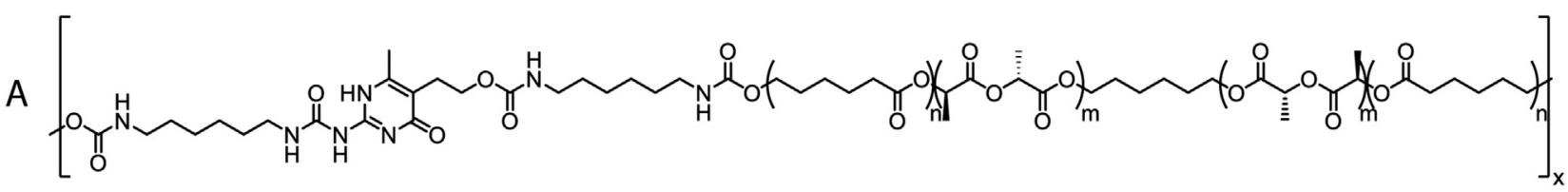

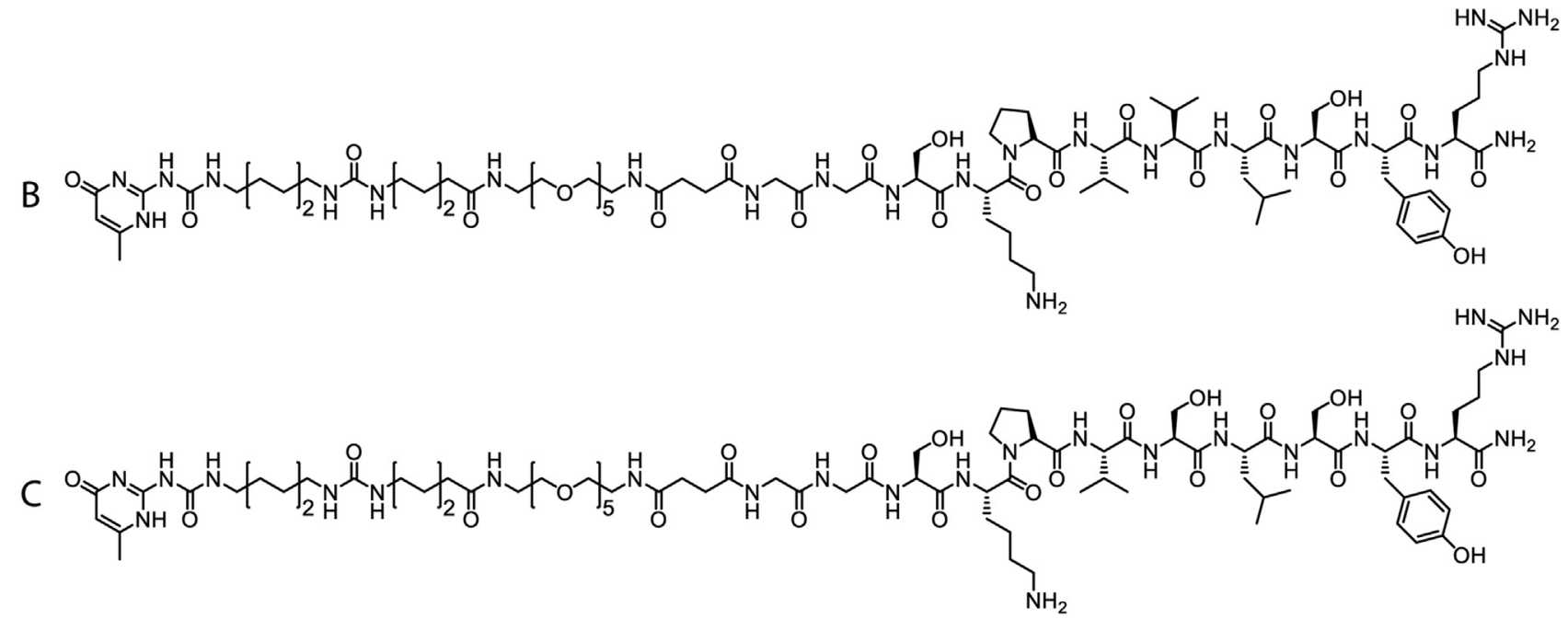

Fig. 1. Chemical structures of used peptides and polymers. A: Chain-extended UPy-poly[L-lactide-co-caprolactone] (CE-UPy-PLLCL) prepolymer $\left(\mathrm{M}_{\mathrm{n}, \mathrm{PLCL}}=1 \mathrm{kDa}\right)$ ) B: UPy$\mathrm{SDF} 1 \alpha(\mathrm{NR})(\mathrm{MW}=1918 \mathrm{Da}) ; \mathrm{C}: \mathrm{UPy}-\mathrm{SDF} 1 \alpha(\mathrm{R})(\mathrm{MW}=1930 \mathrm{Da})$.

\subsection{Cell culture, migration and adhesion assays}

\subsubsection{PBMC isolation}

The study conforms to the principles outlined in the Declaration of Helsinki [28]. For migration assays, adhesion assays and culture experiments peripheral blood was collected via a specific department for blood donation for scientific purposes (minidonordienst, University Medical Center Utrecht, the Netherlands). For analyses performed in the pulsatile-flow bioreactor buffy coats were obtained from Sanquin Blood Supply (Sanquin, Amsterdam, the Netherlands). PBMCs were isolated using Ficol Paque PLUS (Cat. \#17-1440-02, GE healthcare Life Sciences, Diegem, Belgium) density gradient centrifugation according to the manufacturer's protocol and resuspended in DMEM for the adhesion and migration assays or RPMI for the bioreactor. Culture media were supplemented with $10 \%$ fetal calf serum (FCS) and $1 \%$ penicillin/streptomycin except for the migration experiments, which were performed without FCS.

\subsubsection{Migration assay}

Migration assays were performed in a Boyden transwell chamber with $5 \mu \mathrm{m}$ pores (Cat\# 3421, Corning, Lowell, Massachusetts, USA). One million PBMCs were applied to the upper chamber in serum-free medium and allowed to migrate to the bottom compartment, which contained either full-length SDF1 $\alpha$ (cat\#167300-28A-B, Peprotech), or one of the following peptide sequences: SKPVVLSYR, GGSKPVVLSYR, SKPVSLSYR or GGSKPVSLSYR. The assay was performed for $4 \mathrm{~h}$ at $37^{\circ} \mathrm{C}$. Results were compared to the migration of PBMCs in the absence of the SDF1 $\alpha$-derived peptides in serum free medium. A specific CXCR4 (the SDF1 $\alpha$ receptor) inhibitor AMD3100 $(50 \mu \mathrm{M})$ was incubated with the PBMCs in serum free medium for $30 \mathrm{~min}$ before the cells were transferred to the migration chamber. After migration the cells in the lower compartment were collected, including cells adhering to the bottom of the membrane, which were rinsed off, and re-suspended and counted after 1:1 dilution in trypan blue (cat\# 15250-061, Life Technologies) using a hematocytometer.

\subsubsection{Adhesion assay}

Adhesion assays were performed on dropcast films of CE-UPyPLLCL containing $1.1 \mathrm{~mol} \%$ of UPy-SDF1 $\alpha(\mathrm{R})$ peptide or UPySDF1 $\alpha(N R)$ peptide, and compared to pristine UPy-PLLCL substrates. The dropcast films were by casting $5 \mathrm{w} / \mathrm{v} \%$ polymer/peptide solution in HFIP onto $15 \mathrm{~mm}$ round glass coverslips and left to dry for $24 \mathrm{~h}$ followed by additional incubation at $40{ }^{\circ} \mathrm{C}$ in vacuo to remove residual solvent. One million PBMCs were seeded on the polymer films in DMEM supplemented with 10\% FCS and $1 \%$ penicillin/streptomycin for $30 \mathrm{~min}$ before being rinsed with phosphate buffered saline (PBS). Cells were fixed using $4 \%$ paraformaldehyde/PBS and stained using 4',6-diamidino-2phenylindole (DAPI). Cell numbers were quantified per $400 \times$ magnified field.

\subsubsection{Cell recruitment in a mesofluidic device by electrospun scaffolds}

Cell recruitment under pulsatile flow conditions was analyzed using a mesofluidic device connected to an Ibidi flow system [15]. Electrospun sheets were prepared from CE-UPy-PLLCL with UPySDF1 $\alpha(R)$ peptide or UPy-SDF1 $\alpha(\mathrm{NR})$ peptide, and compared to pristine CE-UPy-PLLCL. In order to achieve a physiologically relevant cell concentration, $5 \cdot 10^{7}$ PBMCs were resuspended in $10 \mathrm{~mL}$ medium for each flow-chamber. A dual syringe-pump created a unidirectional flow by applying continuous pressure at $120 \mathrm{mmHg}$. A pulsatile flow was created by intermittent mechanical pinching of the inlet tube. Electrospun meshes $(10 \times 15 \mathrm{~mm})$ where placed in a custom designed chamber, allowing flow to pass underneath the material. After 2 or $14 \mathrm{~h}$ the circulation was stopped and the electrospun material was collected along with the non-adhering cells in the medium.

\subsubsection{In vivo evaluation of peptide-containing electrospun grafts}

All procedures were approved by the institutional Animal Care 
and Use Committee of the University of Utrecht, the Netherlands. Eighteen healthy male Sprague Dawley rats (350-450 g), purchased from Charles River Laboratories received an electrospun aortic interposition graft. Rats were divided in three groups: the first group received a graft composed from CE-UPy-PLLCL material with UPy-SDF1 $\alpha(R)$ peptide, the second group received the same graft but with UPy-SDF1 $\alpha(\mathrm{NR})$ peptide, and the third group served as a control group receiving scaffolds of pristine CE-UPy-PLLCL ( $n=6$ per group). Grafts were explanted at day $1(n=9)$ or day $7(\mathrm{n}=9)$. To inhibit transmural and transanastomotic ingrowth of cells within the first week, all grafts were shielded with Gore-Tex ${ }^{\circledR}$ : Distally and proximally of each electrospun graft an end-to-end anastomosis was made to a $4.10 \mathrm{~mm}^{2}$ impenetrable Gore-Tex strip (Preclude Pericardial Membrane; Gore Medical). In addition to shielding the anastomoses, Gore-Tex was also wrapped around the grafts creating a barrier for cells migrating from the adjacent tissue. Animals were anaesthetized using isoflurane gas. Explants were cut in half and fixed in $10 \%$ formalin for immunohistochemistry and Trizol for qPCR.

\subsection{Immunohistochemistry}

In vitro samples were fixed in 3.7\% formaldehyde/PBS and blocked in PBS/BSA $2 \%$ for $1 \mathrm{~h}$, after which primary antibodies against CD3 and CD14 (Serotec) were incubated for $1 \mathrm{~h}$ at room temperature. Secondary antibodies (goat anti rabbit-cy5, goat anti mouse AF568) were incubated for $1 \mathrm{~h}$ at room temperature shielded from the light. Nuclei were stained with DAPI for $10 \mathrm{~min}$ in the dark. Confocal microscopy (Zeiss LSM700) was used to image the cells. Cell numbers were quantified per $40 \times$ magnification. For in vivo samples, before pre-embedding in $1 \%(\mathrm{w} / \mathrm{v})$ agar (Eurogentec), explants were fixed in $10 \%$ formalin followed by embedding in paraffin. Consecutive $4 \mu \mathrm{m}$ sections were stained with Mayer's hematoxylin and eosin (H\&E). Immunohistochemical stainings were performed after deparaffinization and dehydration. Sections were stained for CD3, CD68, CD34 and aSMA. Investigators were blinded to the experimental groups and the time point of explantation. Photographs were taken using a Nikon E800 microscope with ACT-1 software. Cellularity was studied under highpower magnification (high-power field, $40 \times$ objective lens; area comprising $0.034 \mathrm{~mm}^{2}$ ). Using ImageJ software, the total number of cells in 4 random hpf areas per graft was manually counted. Area of positive staining was measured as a percentage of the total from binarised images.

\section{4. $q P C R$}

Total RNA was extracted using Trizol according to the manufacturer's protocol (TRIzol, cat\#10296-010, Invitrogen, Life Technologies Europe BV, Bleiswijk, the Netherlands). The electrospun mesh was homogenized in Trizol using a Precellys 24 tissue homogenizer (Precellys, Bertin Technologies, Aix-en Provence, France). cDNA was synthesized using iScript according to the manufacturer's protocol (iScript, Cat\#170-8891, Bio-Rad, Hercules, California, United States). qPCR was analyzed using the delta-delta CT method, normalized to P0 expression.

\subsection{Statistics}

\subsubsection{Data are presented as mean \pm standard deviation}

Statistical analysis was performed using one-way analysis of variance (ANOVA) with post-hoc Tukey or post-hoc Dunnett test, student's $\mathrm{T}$ test and Mann-Whitney test where appropriate. $\mathrm{P}$ value $<0.05$ was considered statistically significant.

\section{Results}

3.1. Synthetic SDF1 $\alpha$-derived peptides are biologically active through CXCR4 and are resistant to proteolytic degradation by MMP2

The ability of the SDF1 $\alpha$-derived peptides to induce receptormediated migration was analyzed to confirm biological activity though the SDF1 $\alpha$-CXCR4 axis. In a Boyden chamber migration assay both $\operatorname{SDF} 1 \alpha(\mathrm{R})$ and SDF1 $\alpha(\mathrm{NR})$ peptides induced significant migration of PBMCs compared to the non-peptide control condition and to a similar degree to full-length SDF1 $\alpha$. Pre-incubation of PBMCs with the CXCR4-specific antagonist AMD-3100 significantly reduced the number of migrating cells (Fig. 2A). This indicates that the short peptides retain their receptor-mediated SDF1 $\alpha$ activity.

Sensitivity to proteolytic degradation by matrix metalloproteinases was studied via incubation of GGSKPVSLSYR and GGSKPVVLSYR peptides in the presence of MMP-2. MMP-2 is known to selectively hydrolyze the peptide bond between the serine and valine residues within the SDF peptide, yielding a LSYRpeptide fragment with a typical molecular weight of 537.3 Da. LCMS analysis of the GGSKPVSLSYR-peptide revealed a distinct peak in the chromatogram after proteolytic degradation, corresponding to the LSYR-fragment at 537.3 Da, which was not observed prior to incubation with MMP-2. The LSYR-fragment was also found after exposure of the GGSKPVVLSYR to MMP-2, but at levels close to the detection limit of the LC-MS apparatus, and therefore considered non-significant (Supplemental Fig. 1).

The adhesion of PBMCs to films modified with the UPy-SDF1 $\alpha$ derived peptides was studied by culturing the cells for $30 \mathrm{~min}$ on these materials. On films containing the UPy-SDF1 $\alpha(R)$ peptides significantly more PBMCs were adhered (Fig. 2B) compared to pristine CE-UPy-PLLCL.The UPy-SDF1 $\alpha(\mathrm{NR})$ peptides showed a similar trend for more adhered PBMCs though no statistical significance was found (Fig. 2B). Together these results demonstrate that substitution of the serine residue with a valine indeed abolished rapid proteolytic degradation of the SDF1 $\alpha$-derived peptides, and that the peptides retained their activity after incorporation into UPy-PLLCL.

Electrospun fibers functionalized with UPy-SDF1 $\alpha(\mathrm{R})$ peptides or UPy-SDF1 $\alpha(\mathrm{NR})$ peptides retain lymphocytes under pulsatile flow conditions in vitro and reduce inflammatory protein expression.

SEM analysis of the electrospun meshed showed a fiber diameter of $2.3 \mu \mathrm{m}( \pm 0.3 \mu \mathrm{m})$ for both peptide materials and $3.2 \mu \mathrm{m}$ $( \pm 0.4 \mu \mathrm{m})$ for control CE-UPy-PLLCL (Supplemental Fig. 2), which enables cells to migrate into the mesh [16]. Electrospun meshes were exposed to a physiological concentration of $5 \cdot 10^{6}$ cells $/ \mathrm{mL}$ of PBMCs in a custom-designed bioreactor under an unidirectional pulsatile flow [15]. Both the CE-UPy-PLLCL/UPy-SDF1 $\alpha(\mathrm{R})$ peptide scaffold and pristine material, analyzed by SEM, showed cellular adhesion throughout the fibers (Fig. 3). The cells appeared flattened and well-adhered with some cells showing a round morphology. Confocal microscopy on the lymphocyte marker CD3 and the monocyte marker CD14 shows that the adhering cells after $2 \mathrm{~h}$ of flow were predominantly lymphocytes and monocytes with no significant differences between materials (Supplemental Fig. 3). After $14 \mathrm{~h}$ of flow, however, markedly more CD3+ lymphocytes and less CD14+ monocytes were found in both UPy-SDF1 $\alpha(R)$ peptide and UPy-SDF1 $\alpha(\mathrm{NR})$ peptide materials (Fig. 4), indicating a specific retention of lymphocytes by the peptides after $14 \mathrm{~h}$.

After $2 \mathrm{~h}$ of flow, analysis by qPCR showed a significantly higher expression of CD3 (a lymphocyte marker) and CD8 (a cytotoxic tcell marker) in the UPy-SDF1 $\alpha(\mathrm{R})$ modified material indicating an initial predominance of cytotoxic t-cells (Supplemental Fig. 3). This 
A

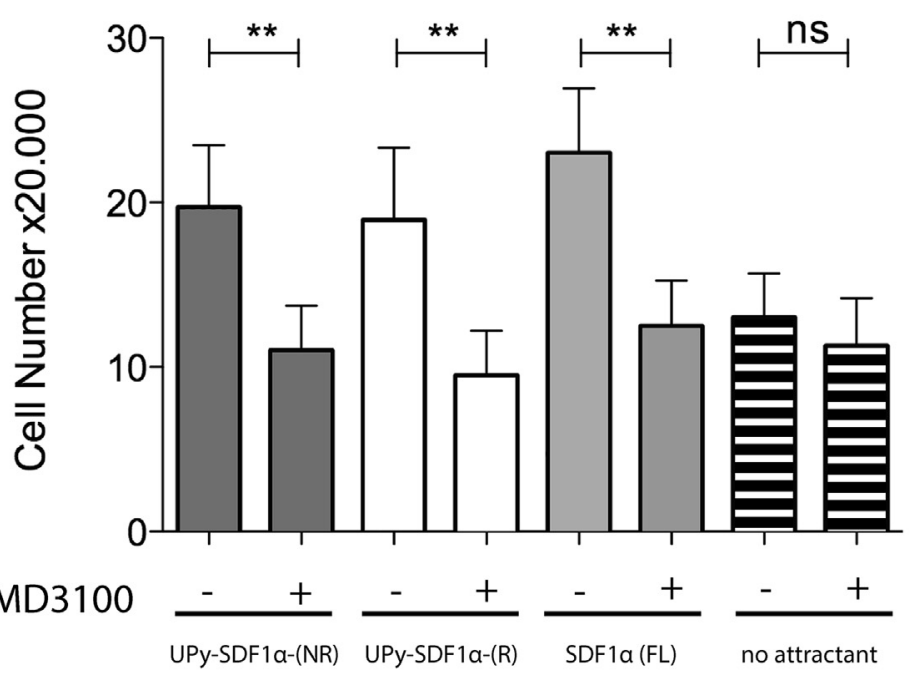

B

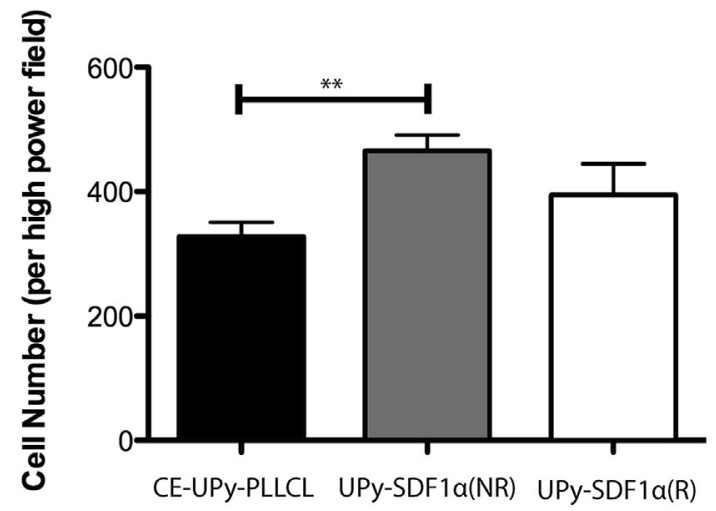

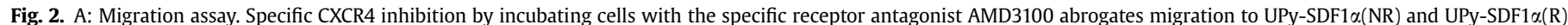

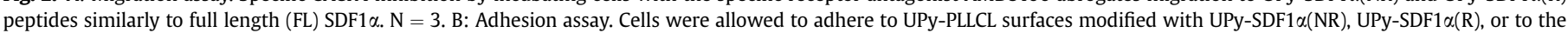
pristine polymer surface (CE-UPy-PLLCL). Nuclei were counted per high-power field. CE-UPy-PLLCL with UPy-SDF1 $\alpha(\mathrm{R})$ adhered significantly more PBMCs. $\mathrm{P}=0.007, \mathrm{~N}=6$.

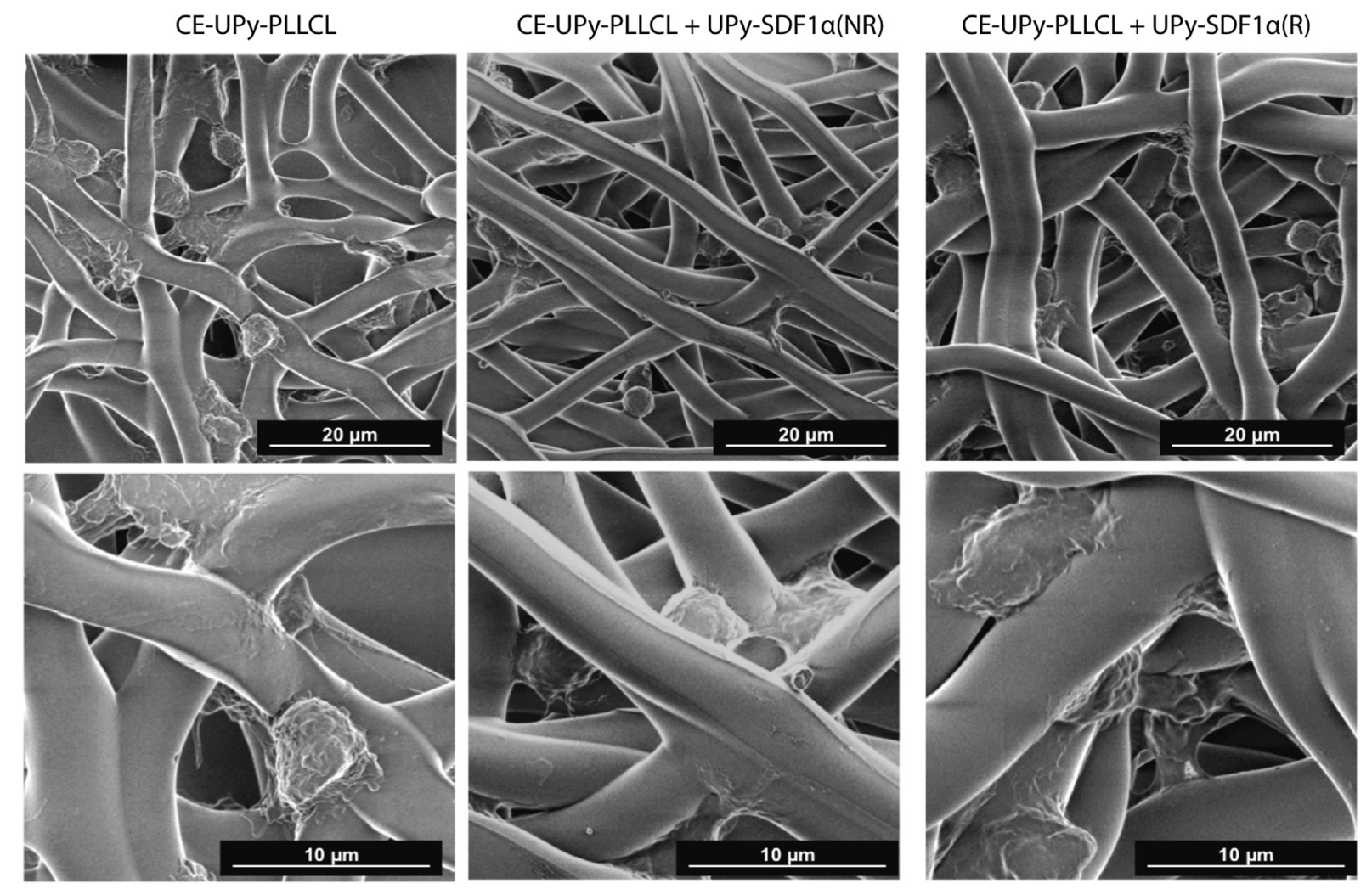

Fig. 3. SEM of electrospun meshes after $14 \mathrm{~h}$ of exposure to PBMCs under pulsatile flow in vitro. Cells adhere to the fibers.

pattern changed after $14 \mathrm{~h}$ when there was a significantly higher expression of CD4 (a t-helper cell marker) while the expression of CD8 was lower. At this time point a trend for higher expression of CD3 in peptide materials was found, consistent with the immunohistological stainings. This implies an enhanced recruitment of thelper cells (Fig. 4) in peptide-functionalized scaffolds. In addition, we found significantly lower expression of the inflammatory proteins MCP1 and TNF $\alpha$ in peptide material after $14 \mathrm{~h}$ but not after $2 \mathrm{~h}$. Concordantly the expression of the lymphocyte activation marker CD25 was significantly lowered at this time point. ELISA performed on the circulating medium showed no significant differences between protein concentrations of anti-inflammatory protein IL10 and pro-inflammatory protein TNFa after $14 \mathrm{~h}$ (Supplemental Fig. 4).

\subsection{UPy-SDF1a peptides increase cellularization in electrospun vascular grafts in vivo}

Electrospun tubular scaffolds were implanted into interposition grafts in rat abdominal aortas and explanted for histological 
A

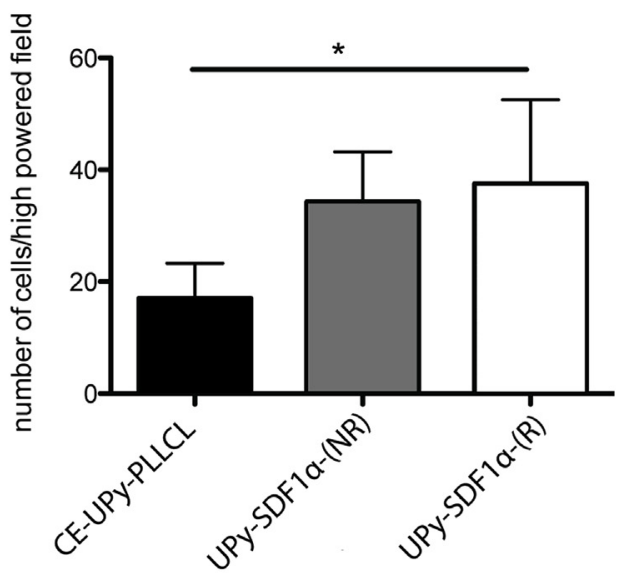

B

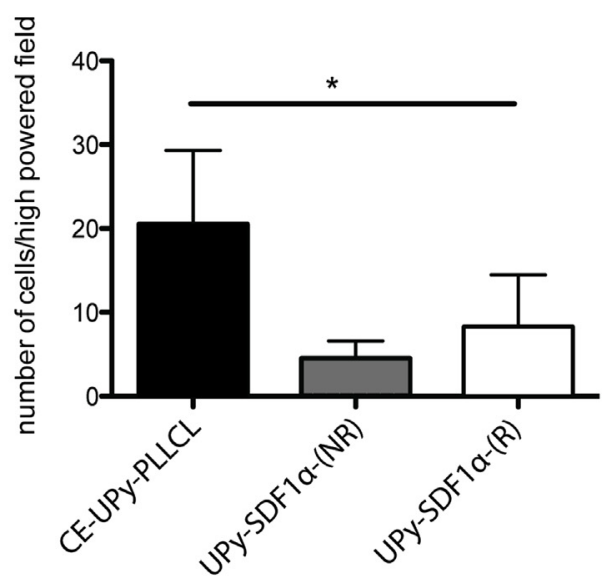

C

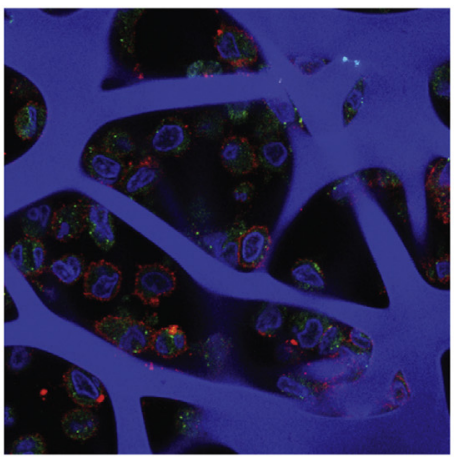

CE-UPy-PLLCL

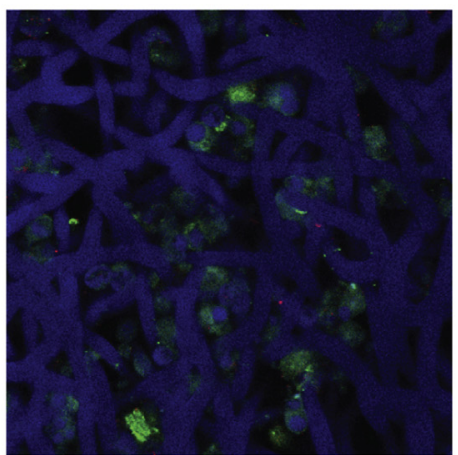

UPy-SDF1a-(NR)

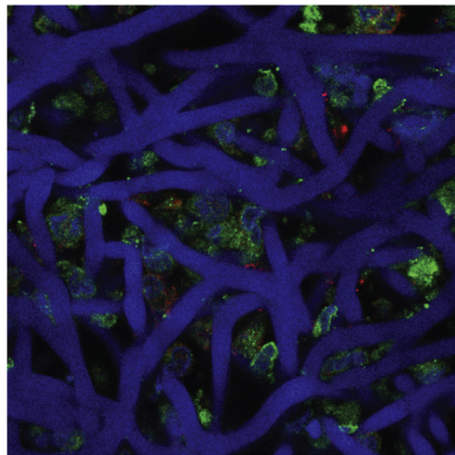

UPy-SDF1a-(R)

D

Expression in adhering cells after $\mathbf{1 4}$ hours in pulsatile flow

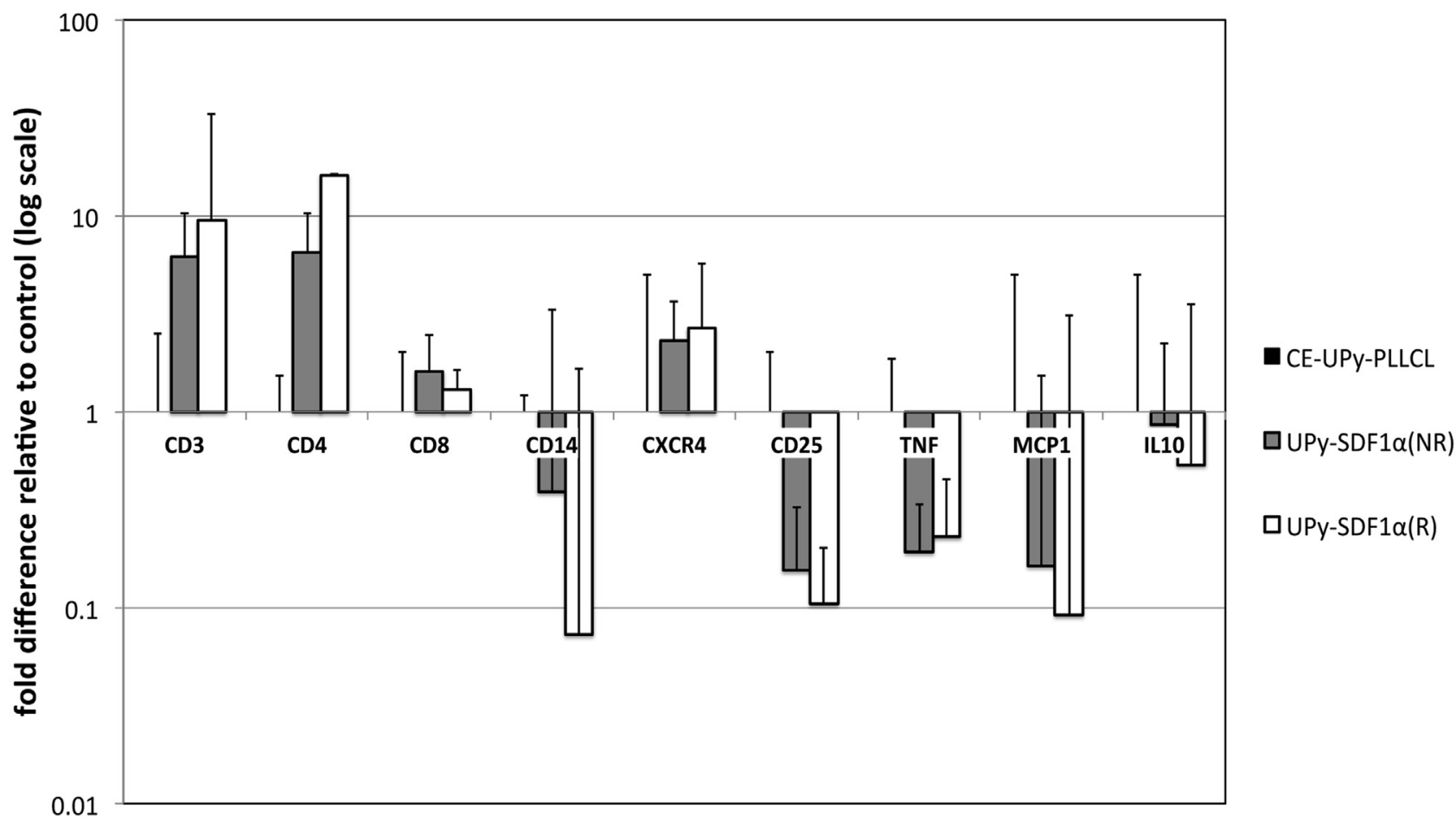

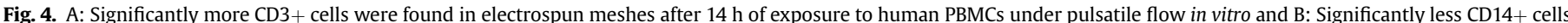

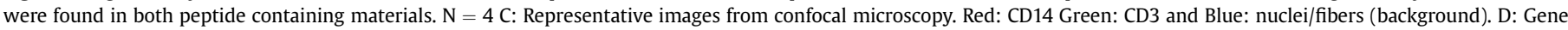

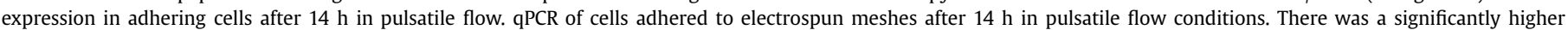

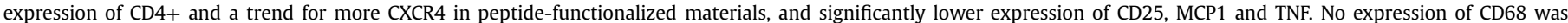
detected. (For interpretation of the references to color in this figure legend, the reader is referred to the web version of this article.) 
analysis after $24 \mathrm{~h}$ and 7 days. After $24 \mathrm{~h}$, predominantly granulocytes and macrophages had infiltrated the scaffold, based on cell morphology. After 7 days cellularity had increased to $89 \pm 15$ cells per (high power field) hpf in material with UPy-SDF1 $\alpha(N R)$ and $88 \pm 6$ cells per hpf in material with UPy-SDF1 $\alpha(R)$ while the control group showed $51 \pm 12$ cells per hpf. This increased cellularity was significant at day 7 in material with UPy-SDF1 $\alpha(\mathrm{NR})$ $(\mathrm{p}=0.03)$ and material with $\mathrm{UPy}-\mathrm{SDF} 1 \alpha(\mathrm{R})(\mathrm{p}=0.02)$ compared to the control group (Fig. 5). At this time point the cells were predominantly present in deeper layers of both peptide materials while control material showed most cells near the luminal side indicating that the peptides influenced cell migration (Fig. 5). For this in vivo analysis CD68 was used as a macrophage marker. The amount of CD68+ cells was also significantly higher at day 7 in UPy-SDF1 $\alpha(\mathrm{NR})$ material compared to the control group $(\mathrm{p}=0.02)$ (Fig. 5), having increased to $2.53 \% \pm 0.53 \%$ in material with UPySDF $1 \alpha(N R)$ and $2.35 \% \pm 1.15 \%$ in material with UPy-SDF1 $\alpha(R)$ compared to $0.07 \% \pm 0.01 \%$ in the control group. No CD3+ cells were detected by immunohistochemistry. There was a trend for higher number of CD34 and aSMA positive cells in both peptidecontaining materials after 7 days, though no significant differences were found (Supplemental Fig. 5).

\section{Discussion}

Previous efforts to use biofunctionalized synthetic materials for vascular grafting have mostly focused on ECM derived peptides such as RGD to enhance cellular adhesion [17]. Considering their ability to simultaneously attract and stimulate targeted cell populations chemokines may provide more specific biological activity. We report, for the first time, that the supramolecular bioactivation of a fully synthetic material using short peptides based on the chemokine SDF1 $\alpha$ can attract and stimulate cells into a cell-free vascular replacement graft scaffold. The supramolecular mix-andmatch approach combined with electrospinning enables control over the structural and biochemical properties of the graft, which can greatly influence cellular influx and behavior [18-20]. Electrospinning yields fibrous mesh scaffolds that form a 3dimensional microenvironment of microfibers that allow cellular infiltration throughout the graft [16]. We used a supramolecular approach to modify these electrospun fibers with bioactive molecules using UPy-moieties [12]. This surface presentation of the peptides facilitated the binding to the receptor CXCR4 and mimics the in vivo interaction of matrix-bound chemokines with cells in tissue damage repair [2]. In our in vitro analyses, specific retention of human PBMCs due to the peptides becomes apparent after $14 \mathrm{~h}$. In addition, expression was significantly lowered for the inflammatory proteins MCP1 and TNF $\alpha$ after $14 \mathrm{~h}$, which indicates that the presence of the peptides reduces inflammatory signaling by the adhering cells in an early stage of cellular influx. Consistent with the chemoattractive function of SDF1 $\alpha$ in vivo, after 7 days of implantation of scaffolds in an abdominal aorta interposition graft, the distribution of the infiltrating cells within the graft material was more homogenous with deeper penetration in scaffolds containing UPy-SDF $1 \alpha(\mathrm{R})$ peptides or UPy-SDF $1 \alpha(\mathrm{NR})$ peptides compared to control material. The additional penetration of cells seen in the peptide-containing materials may be due to the production of signaling proteins by the adhering cells induced by interaction through the CXCR4-SDF1a axis. In contrast, cell retention due to a generic immune response and hemodynamic pressure was restricted to the luminal side of the graft in material without peptides. Furthermore, the higher number of CD68+ cells and

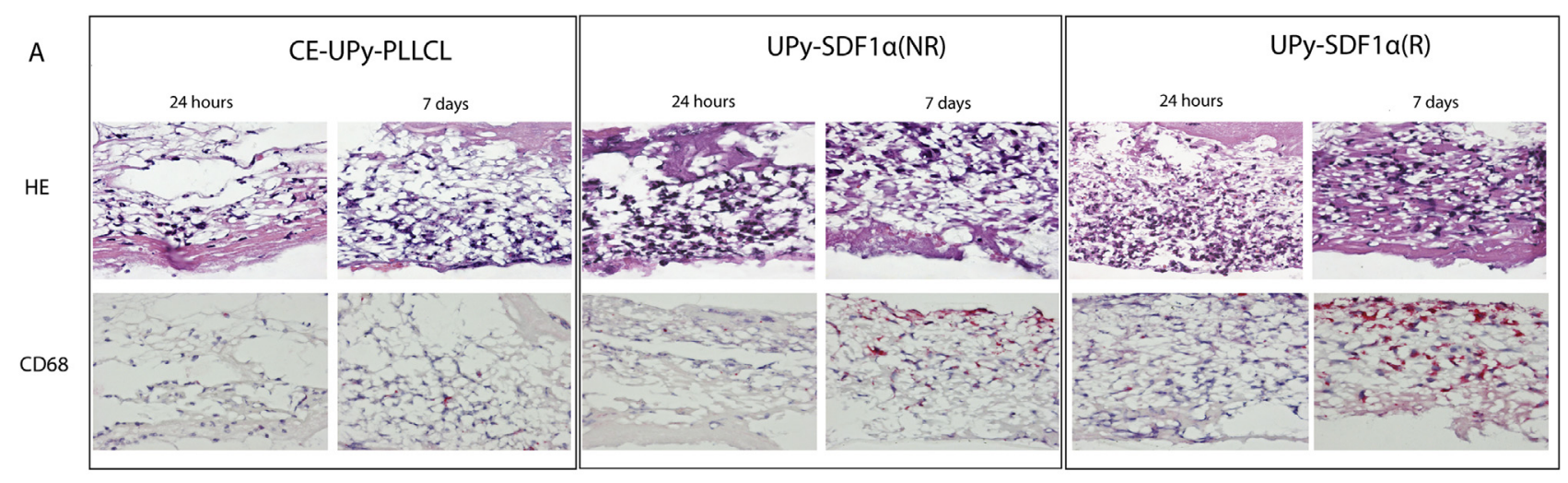

B
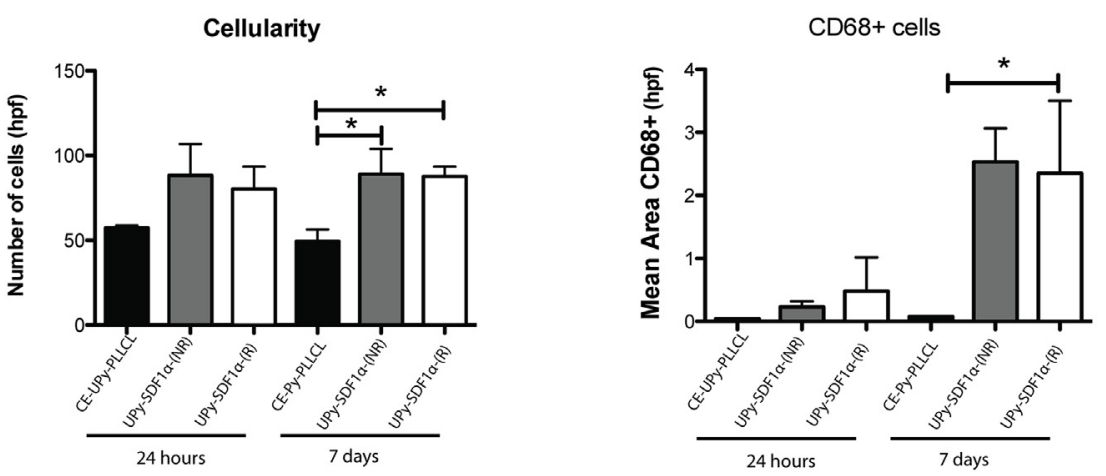

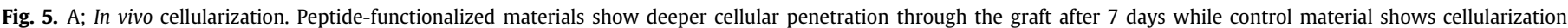

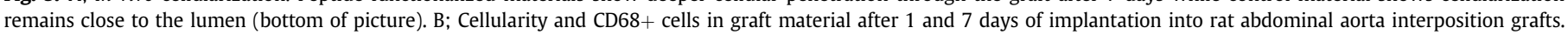
Cellularity and CD68+ cell count is significantly raised in both peptide-functionalized materials after 7 days. 
reduced number of lymphocytes found in-vivo differs from the higher number of lymphocytes found early timepoints in-vitro. It is likely that the early retention of lymphocytes found in vitro influenced the subsequent attraction of additional monocytes in our in vivo model, which contains a replenishing immune system in contrast with the in vitro model.

Flameng et al. recently showed that pre-existing, decellularized heart valves coated with fibronectin and full length SDF1 $\alpha$ protein developed fully recellularized vascular tissue in vivo after 5 months in sheep, due to the presentation of the full length SDF1 $\alpha$ protein by fibronectin [7]. This further illustrates that mimicking the molecular dynamics of chemokines is of great potential in tissue engineering strategies. Molecular re-design of the SDF1 $\alpha$ protein has previously improved applicability in tissue damage repair applications, but not yet tissue engineering. Enhancing the interaction between cells and chemokines by influencing molecular presentation is a promising approach to bio-activating materials. By fusing SDF1 $\alpha$ to a glycoprotein VI (GPVI)-domain, which binds to collagen, Ziegler et al. were able to increase the localization of intravenously injected recombinant protein to the site of myocardial infarction [21]. Schesny et al. exploited the resulting enhanced matrixbinding to incorporate it into poly(ethylene glycol) based hydrogels as a delivery tool to treat ischemic cardiovascular disease [22]. While the above-mentioned research focuses on damage repair in pre-existing living tissues, our data shows, for the first time, that SDF1 $\alpha$-derived peptides are also of great potential in enhancing developing new tissue in fully synthetic cell-free grafts.

In cell-free grafts, early cellularization is pivotal for neotissue formation [23]. A systemic response to implanted foreign material involves early invasion by monocytes, lymphocytes and progenitor cells from the circulation. In vivo, these cells dictate the inflammatory signaling environment of tissue regeneration [24,25], among others influencing the polarization of macrophage subtypes $[26,27]$, which is an important step in the progression to a protissue repair phase. There is evidence that one of the mechanisms in which SDF1 $\alpha$ induces tissue repair is through influencing the development of CD68 monocytes towards a pro-tissue formation phenotype [7]. The differentiation of monocytes into macrophages is an important step in the regulation of tissue development and remodeling, and is greatly influenced by signaling factors produced by cells in the microenvironment. In particular, alternatively activated macrophages, or M2 macrophages, have been associated with improved tissue formation in tissue engineered implanted constructs $[28,29]$. There is evidence that SDF1a can induce the polarization of monocytes towards an M2 phenotype [30,31]. Our in vivo data show that short-term implantation of UPy-SDF1 $\alpha(\mathrm{R})$ peptide or UPy-SDF1 $\alpha(\mathrm{NR})$ peptide materials in an abdominal aorta interposition graft in rat increased cellularity by CD68+ monocytes after 7 days, indicating that the early signaling environment triggered by the peptides directly influences subsequent cellularization.

In an inflammatory environment the presence of the enzymes MMP2 and CD26 are an important limiting factor of the longevity of the wild-type SDF1 $\alpha$ protein $[8,14,32,33]$. For this reason resistance to enzymatic degradation is highly desirable to promote cellular infiltration and ultimately neotissue formation over a longer period of time. Longer implantation timepoints will help to investigate the potentially prolonged activity of UPy-SDF1 $\alpha(\mathrm{R})$ peptides in vivo. Though we found no significant advantage of resistant peptides over non-resistant peptides in our early in vivo time point analyses, our in vitro data consistently shows a stronger effect of UPySDF1 $\alpha(R)$ over UPy-SDF1 $\alpha(\mathrm{NR})$.

Our results provide a first step towards in situ cardiovascular tissue engineering by combining electrospinning with the advantages of supramolecular chemistry, through non-covalent functionalization of scaffold material with short peptides based on SDF1 $\alpha$. Our data show that we have achieved bio-instructive scaffold materials that can enhance the cellularization of implanted vascular replacement grafts. Due to the fully synthetic approach and the versatility of the supramolecular introduction of bioactive molecules, we propose that our approach is highly translatable to diverse cardiovascular clinical applications.

\section{Acknowledgments}

This research forms part of the Project P1.01 iValve of the research program of the BioMedical Materials institute, co-funded by the Dutch Ministry of Economic Affairs.

The financial contribution of the Nederlandse Hartstichting is gratefully acknowledged.

Part of this research is funded by the Ministry of Education, Culture and Science (Gravity program 024.001.035), the Netherlands Organisation for Scientific Research (NWO), the European Research Council (FP7/2007-2013), ERC Grant Agreement 308045 and the Netherlands Institute for Regenerative Medicine (NIRM) (Grant No. FES0908).

\section{Appendix A. Supplementary data}

Supplementary data related to this article can be found at http:// dx.doi.org/10.1016/j.biomaterials.2015.10.052.

\section{References}

[1] H. Kurobe, M.W. Maxfield, C.K. Breuer, T. Shinoka, Concise review: tissueengineered vascular grafts for cardiac surgery: past, present, and future, Stem Cells Transl. Med. 1 (2012) 566-571, http://dx.doi.org/10.5966/ sctm.2012-0044.

[2] D.E.P. Muylaert, J.O. Fledderus, C.V.C. Bouten, P.Y.W. Dankers, M.C. Verhaar Combining tissue repair and tissue engineering; bioactivating implantable cell-free vascular scaffolds, Heart 100 (2014) 1825-1830, http://dx.doi.org/ 10.1136/heartjnl-2014-306092.

[3] D.S.T. Chong, B. Lindsey, M.J. Dalby, N. Gadegaard, A.M. Seifalian, G. Hamilton, Luminal surface engineering, "micro and nanopatterning": potential for self endothelialising vascular grafts? Eur. J. Vasc. Endovasc. Surg. 47 (2014) 566-576, http://dx.doi.org/10.1016/j.ejvs.2014.02.007.

[4] C. Dürr, D. Pfeifer, R. Claus, A. Schmitt-Graeff, U.V. Gerlach, R. Graeser, et al., CXCL12 mediates immunosuppression in the lymphoma microenvironment after allogeneic transplantation of hematopoietic cells, Cancer Res. 70 (2010) 10170-10181, http://dx.doi.org/10.1158/0008-5472.CAN-10-1943.

[5] C.C. Bleul, R.C. Fuhlbrigge, J.M. Casasnovas, A. Aiuti, T.A. Springer, A highly efficacious lymphocyte chemoattractant, stromal cell-derived factor 1 (SDF-1), J. Exp. Med. 184 (1996) 1101-1109.

[6] A. Hidalgo, F. Sanz-Rodríguez, J.L. Rodríguez-Fernández, B. Albella, C. Blaya, N. Wright, et al., Chemokine stromal cell-derived factor-1alpha modulates VLA-4 integrin-dependent adhesion to fibronectin and VCAM-1 on bone marrow hematopoietic progenitor cells, Exp. Hematol. 29 (2001) 345-355.

[7] W. Flameng, G. De Visscher, L. Mesure, H. Hermans, R. Jashari, B. Meuris, Coating with fibronectin and stromal cell-derived factor- $1 \alpha$ of decellularized homografts used for right ventricular outflow tract reconstruction eliminates immune response-related degeneration, J. Thorac. Cardiovasc. Surg. 147 (2014), http://dx.doi.org/10.1016/j.jtcvs.2013.06.022, 1398-1404.e2.

[8] V.F.M. Segers, T. Tokunou, L.J. Higgins, C. MacGillivray, J. Gannon, R.T. Lee Local delivery of protease-resistant stromal cell derived factor- 1 for stem cell recruitment after myocardial infarction, Circulation 116 (2007) 1683-1692. http://dx.doi.org/10.1161/CIRCULATIONAHA.107.718718.

[9] J. Yu, A. Wang, Z. Tang, J. Henry, B. Li-Ping Lee, Y. Zhu, et al., The effect of stromal cell-derived factor- $1 \alpha /$ heparin coating of biodegradable vascular grafts on the recruitment of both endothelial and smooth muscle progenitor cells for accelerated regeneration, Biomaterials 33 (2012) 8062-8074, http:// dx.doi.org/10.1016/j.biomaterials.2012.07.042.

[10] T. Sugiyama, H. Kohara, M. Noda, T. Nagasawa, Maintenance of the hematopoietic stem cell pool by CXCL12-CXCR4 chemokine signaling in bone marrow stromal cell niches, Immunity 25 (2006) 977-988, http://dx.doi.org/10.1016/ j.immuni.2006.10.016.

[11] D.E.P. Muylaert, D.E. Muylaert, J.O. Fledderus, J.O. Fledderus, C.V.C. Bouten, C.V. Bouten, et al., Combining tissue repair and tissue engineering; bioactivating implantable cell-free vascular scaffolds, Heart 100 (2014) 1825-1830, http://dx.doi.org/10.1136/heartjnl-2014-306092.

[12] R.P. Sijbesma, F.H. Beijer, L. Brunsveld, B.J. Folmer, J.H. Hirschberg, R.F. Lange, et al., Reversible polymers formed from self-complementary monomers using 
quadruple hydrogen bonding, Science 278 (1997) 1601-1604

[13] S.H.M. Söntjens, R.A.E. Renken, G.M.L. van Gemert, T.A.P. Engels, A.W. Bosman, H.M. Janssen, et al., Thermoplastic elastomers based on strong and welldefined hydrogen-bonding interactions, Macromolecules 41 (2008) 5703-5708, http://dx.doi.org/10.1021/ma800744c.

[14] V.F.M. Segers, V. Revin, W. Wu, H. Qiu, Z. Yan, R.T. Lee, et al., Protease-resistant stromal cell-derived factor- 1 for the treatment of experimental peripheral artery disease, Circulation 123 (2011) 1306-1315, http://dx.doi.org/10.1161/ CIRCULATIONAHA.110.991786.

[15] A.I.P.M. Smits, A. Driessen-Mol, C.V.C. Bouten, F.P.T. Baaijens, A mesofluidicsbased test platform for systematic development of scaffolds for in situ cardiovascular tissue engineering, Tissue Eng. Part C. Methods 18 (2012) 475-485, http://dx.doi.org/10.1089/ten.TEC.2011.0458.

[16] A. Balguid, A. Mol, M.H. van Marion, R.A. Bank, C.V.C. Bouten, F.P.T. Baaijens, Tailoring fiber diameter in electrospun poly(epsilon-caprolactone) scaffolds for optimal cellular infiltration in cardiovascular tissue engineering, Tissue Eng. Part A 15 (2009) 437-444, http://dx.doi.org/10.1089/ten.tea.2007.0294.

[17] P.Y.W. Dankers, M.C. Harmsen, L.A. Brouwer, M.J.A. van Luyn, E.W. Meijer A modular and supramolecular approach to bioactive scaffolds for tissue engineering, Nat. Mater. 4 (2005) 568-574, http://dx.doi.org/10.1038/ nmat1418.

[18] N.F. Huang, S. Li, Regulation of the matrix microenvironment for stem cell engineering and regenerative medicine, Ann. Biomed. Eng. 39 (2011) 1201-1214, http://dx.doi.org/10.1007/s10439-011-0297-2.

[19] J. Pu, F. Yuan, S. Li, K. Komvopoulos, Electrospun bilayer fibrous scaffolds for enhanced cell infiltration and vascularization in vivo, Acta Biomater. 13 (2015) 131-141, http://dx.doi.org/10.1016/j.actbio.2014.11.014.

[20] D. Sengupta, S.D. Waldman, S. Li, From in vitro to in situ tissue engineering Ann. Biomed. Eng. 42 (2014) 1537-1545, http://dx.doi.org/10.1007/s10439014-1022-8.

[21] M. Ziegler, M. Elvers, Y. Baumer, C. Leder, C. Ochmann, T. Schönberger, et al., The bispecific SDF1-GPVI fusion protein preserves myocardial function after transient ischemia in mice, Circulation 125 (2012) 685-696, http://dx.doi.org/ 10.1161/CIRCULATIONAHA.111.070508.

[22] M.K. Schesny, M. Monaghan, A.H. Bindermann, D. Freund, M. Seifert, J.A. Eble et al., Preserved bioactivity and tunable release of a SDF1-GPVI bi-specific protein using photo-crosslinked PEGda hydrogels, Biomaterials 35 (2014) 7180-7187, http://dx.doi.org/10.1016/j.biomaterials.2014.04.116.

[23] S. Franz, S. Rammelt, D. Scharnweber, J.C. Simon, Immune responses to implants - a review of the implications for the design of immunomodulatory biomaterials, Biomaterials 32 (2011) 6692-6709, http://dx.doi.org/10.1016/ j.biomaterials.2011.05.078.

[24] T. Netelenbos, S. Zuijderduijn, J. Van Den Born, F.L. Kessler, S. Zweegman, P.C. Huijgens, et al., Proteoglycans guide SDF-1-induced migration of hematopoietic progenitor cells, J. Leukoc. Biol. 72 (2002) 353-362.

[25] L. Chen, N.D. Mehta, Y. Zhao, L.A. DiPietro, Absence of CD4 or CD8 lymphocytes changes infiltration of inflammatory cells and profiles of cytokine expression in skin wounds, but does not impair healing, Exp. Dermatol. 23 (2014) 189-194, http://dx.doi.org/10.1111/exd.12346.

[26] M. Weidenbusch, H.-J. Anders, Tissue microenvironments define and get reinforced by macrophage phenotypes in homeostasis or during inflammation, repair and fibrosis, J. Innate Immun. 4 (2012) 463-477, http://dx.doi.org/ $10.1159 / 000336717$.

[27] A. Sica, A. Mantovani, Macrophage plasticity and polarization: in vivo veritas, J. Clin. Invest. 122 (2012) 787-795, http://dx.doi.org/10.1172/JCI59643.

[28] B.N. Brown, R. Londono, S. Tottey, L. Zhang KA. Kukla, MT. Wolf, et al, Macrophage phenotype as a predictor of constructive remodeling following the implantation of biologically derived surgical mesh materials, Acta Biomater. 8 (2012) 978-987, http://dx.doi.org/10.1016/j.actbio.2011.11.031.

[29] Z. Wang, Y. Cui, J. Wang, X. Yang, Y. Wu, K. Wang, et al., The effect of thick fibers and large pores of electrospun poly( $\varepsilon$-caprolactone) vascular grafts on macrophage polarization and arterial regeneration, Biomaterials 35 (2014) 5700-5710, http://dx.doi.org/10.1016/j.biomaterials.2014.03.078.

[30] L. Sanchez-Martin, A. Estecha, R. Samaniego, S. Sanchez-Ramon, M.A. Vega, P. Sanchez-Mateos, The chemokine CXCL12 regulates monocyte-macrophage differentiation and RUNX3 expression, Blood 117 (2011) 88-97, http:/ dx.doi.org/10.1182/blood-2009-12-258186.

[31] C. Brenner, W.M. Franz, S. Kühlenthal, K. Kuschnerus, F. Remm, L. Gross, et al., DPP-4 inhibition ameliorates atherosclerosis by priming monocytes into M2 macrophages, Int. J. Cardiol. 199 (2015) 163-169, http://dx.doi.org/10.1016/ j.ijcard.2015.07.044.

[32] M.-M. Zaruba, H.D. Theiss, M. Vallaster, U. Mehl, S. Brunner, R. David, et al., Synergy between CD26/DPP-IV inhibition and G-CSF improves cardiac function after acute myocardial infarction, Cell Stem Cell 4 (2009) 313-323, http:// dx.doi.org/10.1016/j.stem.2009.02.013.

[33] G.A. McQuibban, G.S. Butler, J.H. Gong, L. Bendall, C. Power, I. Clark-Lewis, et al. Matrix metalloproteinase activity inactivates the CXC chemokine stromal cell-derived factor-1, J. Biol. Chem. 276 (2001) 43503-43508, http:// dx.doi.org/10.1074/jbc.M107736200. 